\title{
Extracellular acidity-induced expression of Kallikrein-related peptidases 7 and 8 is involved in increased invasiveness of gastric cancer cells
}

\author{
SUNG-CHUL LIM ${ }^{1}$, KEUN HONG KEE ${ }^{1}$, MI JALEE ${ }^{1}$, RAN HONG ${ }^{1}$ and SONG IY HAN ${ }^{2}$ \\ ${ }^{1}$ Department of Pathology and ${ }^{2}$ Division of Premedical Science, \\ College of Medicine, Chosun University, Gwangju 61452, Republic of Korea
}

Received October 15, 2019; Accepted February 17, 2020

DOI: $10.3892 /$ or.2020.7529

\begin{abstract}
In several cancers, the acidic microenvironment of cancer cells has been implicated in enhanced malignancy and metastasis. In the present study, it was observed that gastric cancer cell lines, SNU601 and AGS, exposed to an acidic medium had increased invasiveness, as assessed using Matrigel-coated Transwell analysis. The factors regulating such acidity-mediated enhancement of invasiveness were investigated and it was revealed that a low-pH environment markedly increased kallikrein-related peptidase 7 (KLK7) and kallikrein-related peptidase 8 (KLK8) expression. Gene silencing assays confirmed that these peptidases were involved in acidity-promoted invasion. Acidic conditions also increased the expression of cyclooxygenases (COX), key regulatory enzymes in the catalytic pathway of prostaglandin production. Notably, these enzymes appeared to be involved in the acidity-mediated expression of KLK7 and KLK8, as revealed using COX inhibitors. Therefore, it was indicated that tumor invasion enhancement by extracellular acidity is regulated at least in part through the induction of the COX/ KLK7 and KLK8 axis in gastric cancer cells.
\end{abstract}

\section{Introduction}

The ability to invade tissues and metastasize is the major cause of cancer mortality (1-3). Although advances in understanding cancer invasion and metastasis have revealed several important potential molecular targets, treatment of cancer metastasis is still limited. Metastasis occurs through a series of interrelated steps of cell detachment, migration, invasion, and adhesion,

Correspondence to: Dr Song Iy Han, Division of Premedical Science, College of Medicine, Chosun University, Gwangju 61452, Republic of Korea

E-mail: sihan@chosun.ac.kr

Key words: KLK7, KLK8, extracellular acidity, invasion, gastric carcinoma and is controlled by multiple biochemical and signaling pathways. Metastatic processes have recently been suggested to be significantly influenced by microenvironmental factors, such as oxygen levels or $\mathrm{pH}$.

Recent evidence has revealed that the $\mathrm{pH}$ of the microenvironment of solid tumors is relatively acidic due to the accumulation of lactic acid as a result of active aerobic and anaerobic glycolysis (4). Such environmental acidity has been reported to enhance malignant transformation, invasion, and metastasis of several cancer cells. Exposure of melanoma cells to acidic $\mathrm{pH}$ induced acid-resistant and invasive phenotypes (5). Acidic environments also enhanced local invasion and metastasis of human colon cancer cells $(6,7)$. In addition, acidity promoted the malignant progression, induction of cancer stem cell phenotypes, and the epithelial-mesenchymal transition in glioma and melanoma cells $(8,9)$. Although recent studies have revealed that acidity upregulate transcription factors such as NF- $\kappa \mathrm{B}$ and Twistl and is associated with alterations in adherence junction proteins, including E-cadherin, p120-catenin, and $\beta$-catenin, the mechanism by which acidity drives cancer cell invasion is not yet fully understood $(8,9)$.

Currently, multiple lines of evidence have revealed that proteases are involved in cancer invasion and metastasis due to their ability to cleave extracellular matrix components, adhesion molecules, and cytokines (10). Kallikrein-related peptidases (KLKs) are a subgroup of chymotrypsin-like serine proteases composed of fifteen homologous members, KLKs 1-15. KLKs regulate diverse essential physiological processes, and certain KLK members act as signaling regulators that control cell functions through specific membrane receptors, the protease-activated receptors (PARs) (11-14). Notably, several members have been reported to be overexpressed, and therefore, could serve as potential biomarkers for diagnosis and prognosis, in various cancers including ovarian, prostate, pancreatic and cervical cancer $(15,16)$. Therefore, KLKs have been extensively studied for their use as cancer therapeutic targets (17). In the present study, it was revealed that extracellular acidity markedly increased the expression of KLK7 and KLK8 in gastric cancer cell lines and the role of these enzymes in the acidity-mediated invasiveness in these cells was investigated. 


\section{Materials and methods}

Cell culture and $p H$ adjustment. SNU-601 and AGS human gastric cancer (GC) cells were obtained from the Korean Cell Line Bank and the American Type Culture Collection, respectively. Cells were cultured in RPMI-1640 medium (Invitrogen; Thermo Fisher Scientific, Inc.) supplemented with $10 \%(\mathrm{v} / \mathrm{v})$ fetal bovine serum and $1 \% \mathrm{PS}$ at $37^{\circ} \mathrm{C}$ in an atmosphere containing $5 \% \mathrm{CO}_{2}$. For preparation of acidic pH medium, pH 7.4 RPMI-1640 medium containing 1\% FBS medium was prepared, and then adjusted to $\mathrm{pH} 6.5$ or 6.2 by adding $5 \mathrm{M} \mathrm{HCl}$ solution. Sulindac and NS398 were purchased from Calbiochem; EMD Millipore. For Cox inhibition, cells were exposed to $\mathrm{pH} 7.4,6.5$ and 6.2 in the presence of $20 \mu \mathrm{M}$ NS398 or $100 \mu \mathrm{M}$ sulindac for $72 \mathrm{~h}$, and the treated cells were harvested for western blot analysis or real-time PCR assay.

Invasion assay. To assay cell invasiveness, Matrigel-coated Transwell chambers (Costar; Corning Incorporated) were used. Cells in the logarithmic phase were incubated in RPMI-1640 medium containing $1 \%$ FBS, adjusted to $\mathrm{pH} 7.4,6.5$ or 6.2 , for $72 \mathrm{~h}$, after which the number of viable cells that corresponded to the equal absorbance detected in a standard curve for a viability assay were obtained from each $\mathrm{pH}$ condition and suspended in 1\% FBS/RPMI-1640 medium adjusted to each $\mathrm{pH}$ condition (pH 7.4, 6.5 or 6.2 ). Then $\sim 200 \mu \mathrm{l}$ of the cell suspension was added to the upper portion of the insert, and medium containing 5\% FBS was added to the lower portion of the inset. After $8 \mathrm{~h}$ (for AGS) and $18 \mathrm{~h}$ (for SNU601) of incubation at $37^{\circ} \mathrm{C}$ in $5 \% \mathrm{CO}_{2}$, noninvasive cells were removed from the upper surface of the Transwell membrane with a cotton swab, and the invaded cells on the lower layer surface were fixed by $4 \%$ formaldehyde for 15 at RT and stained with $0.5 \%$ crystal violet solution for $10 \mathrm{~min}$ RT. The numbers of invaded cells were counted under high-power magnification (x200) or the images were obtained by image analysis software (analysis FIVE; Olympus Corporation).

Before the invasion assay, a standard curve for viability in each $\mathrm{pH}$ medium was prepared since exposure to acidic $\mathrm{pH}$ medium decreased the number of viable cells. The number of viable cells was determined as follows: Cells cultured for 3 days at each $\mathrm{pH}$ were trypsinized, resuspended in normal $\mathrm{pH}$ medium and further incubated for the time required for invasion measurement, and a standard curve for viability was prepared using an MTT assay. Following MTT incubation, the purple formazan crystals were dissolved using dimethyl sulfoxide and viability was subsequently analyzed at a wavelength of $595 \mathrm{~nm}$. Based on these survival curves, the number of cells corresponding to the same absorbance was calculated and used for this assay.

Western blot analysis. Treated cells were lysed in either a whole-cell lysis buffer (50 mM Hepes, $150 \mathrm{mM} \mathrm{NaCl}$, $1 \%$ Triton X-100, 5 mM EGTA, protease inhibitor cocktail). Protein determination was performed by BCA method. Equal amounts of protein extracts (50 $\mu \mathrm{g}$ of protein per lane) were electrophoretically separated using 10-12\% SDS-PAGE and transferred to a nitrocellulose membrane using a standard technique. Blocking was performed by incubation in $3 \%$ skim milk/0.1\% Tween Tris-buffered saline for $30 \mathrm{~min}$ at $4^{\circ} \mathrm{C}$.
Antibodies were used to probe for KLK7 (dilution 1:500; cat. no. sc-514447; Santa Cruz Biotechnology, Inc.), cyclooxygenase (COX)2 (dilution 1:200; cat. no. 160112; Cayman Chemical), KLK8 (dilution 1:1,000; cat. no. ab150395; Abcam), COX1 (dilution 1:500; cat. no. ab695; Abcam) and $\alpha$-tubulin (dilution 1:2,000; clone no. B-5-1-2; cat. no.32-2500; Invitrogen; Thermo Fisher Scientific, Inc.). The secondary antibodies used were: Anti-rabbit HRP (dilution 1:2,500; cat. no. sc-2030; Santa Cruz Biotechnology, Inc.), anti-mouse HRP (dilution 1:2,500; cat. no. sc-2031; Santa Cruz Biotechnology, Inc.) were used. Anti-a-tubulin was used as a loading control. Protein bands were visualized with the Super Signal West Pico chemiluminescence kit (Pierce Biotechnology; Thermo Fisher Scientific, Inc.). Protein blots were quantified using Alpha Ease FC software version 4.0 (Alpha Innotech). Signals were acquired using an Image Station 4000MM image analyzer (Kodak).

RNA interference (RNAi). For the RNAi experiment, siRNAs of KLK7, KLK8, COX1 and COX2, and a scrambled siRNA control were purchased from Bioneer Corporation. Cells were individually transfected with siRNA oligonucleotides using an Amaxa $^{\mathrm{TM}}$ Transfection System (Lonza Bioscience) and grown for $24 \mathrm{~h}$ prior to exposure to acidic $\mathrm{pH}$ medium.

Real-time reverse transcription-polymerase chain reaction. Real-time PCR was performed with the Light Cycler 2.0 (Roche Diagnostics) using the Fast Start DNA Master SYBR-Green I Kit (Roche Diagnostics). For verification of the correct amplification product, PCR products were analyzed on a $2 \%$ agarose gel stained with ethidium bromide. The sequences of the primers were designed as follows: For $\beta$-actin, 5'-GACTATGACTTAGTTGCGTTA-3' and 5'-GCC TTCATACATCTCAAGTTG-3', for COX1, 5'-GGCGGG TACATTTCTCCATC-3' and 5'-CCTCATGTTTGCCTTCTT TGC-3', for COX2, 5'-AACACAACAGAGTATGCGA-3' and 5'-GTGTTAAATTCAGCAGCAATACG-3'. Primers of KLK7 (product no. P106933), KLK8 (product no. P178536), matrix metalloproteinase 7 (MMP7) (product no. P310408) and matrix metalloproteinase 9 (MMP9) (product no. P323207) were purchased from Bioneer Corporation. PCR was conducted at $95^{\circ} \mathrm{C}$ for $10 \mathrm{~min}$, followed by 45 cycles of $95^{\circ} \mathrm{C}$ for $15 \mathrm{sec}, 60^{\circ} \mathrm{C}$ for $5 \mathrm{sec}$, and $72^{\circ} \mathrm{C}$ for $7 \mathrm{sec}$. Melt curve analysis was performed to confirm that a single product was present. Negative controls without template were included in each run. Data were analyzed using Light Cycler software version 4.0 (Roche Diagnostics). The $2^{-\Delta \Delta C q}$ method was used for analysis of relative gene expression (18).

Detection of KLKs in cell culture supernatants. Cells were incubated in RPMI-1640 medium containing 1\% FBS, adjusted to $\mathrm{pH} 7.4,6.5$ or 6.2 , for $72 \mathrm{~h}$, after which culture medium was obtained and release of KLK7 and KLK8 from cells was assessed using a specific sandwich-type ELISA assay according to established procedures with some modifications (19). Briefly, 96-well polystyrene plates were coated with $500 \mathrm{ng} /$ well of a specific capture antibody. After overnight incubation, the plates were washed and $50 \mu 1$ of culture supernatant or standard and an equal volume of assay buffer were added and incubated for $2 \mathrm{~h}$. Plates were washed and biotinylated antibodies were subsequently added. After 
A SNU601
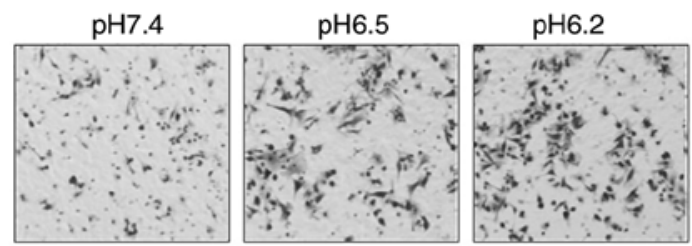

C AGS
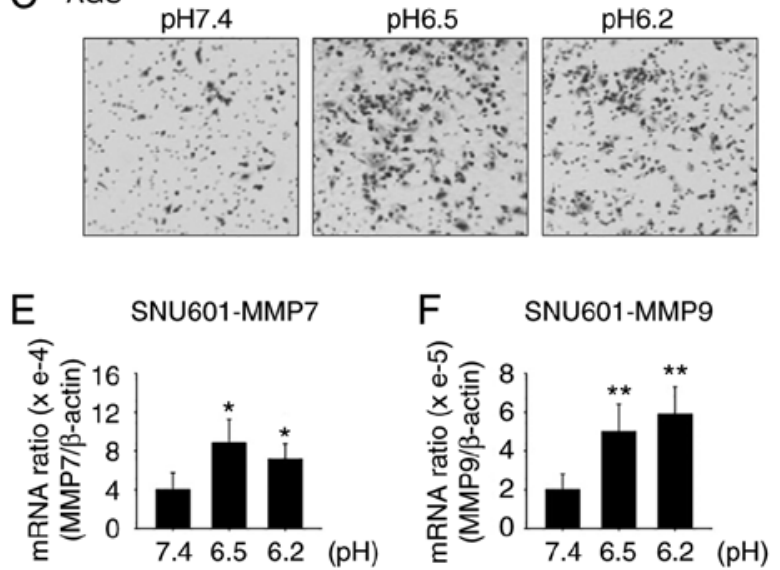

B

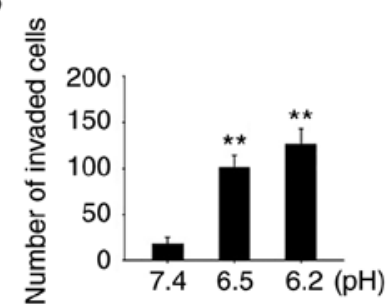

D
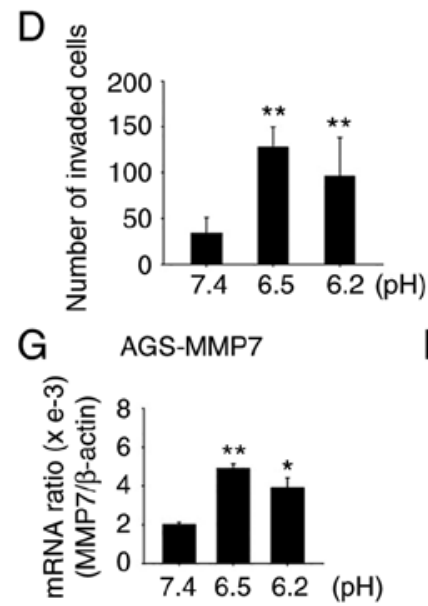

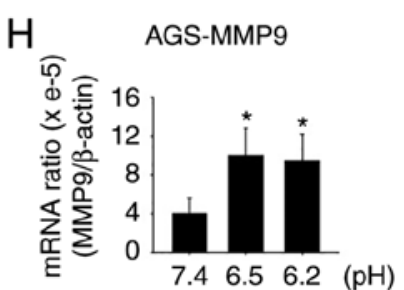

Figure 1. Acidic culture conditions increase invasion of GC cells. (A and B) SNU601 and (C and D) AGS cells exposed to normal (pH 7.4) or acidic (pH 6.5 and 6.2) medium for 3 days were seeded in the Matrigel-coated inner wells of Transwell plates. After $18 \mathrm{~h}$ for SNU601 and $8 \mathrm{~h}$ for AGS, invaded cells were detected (A and C) under a microscope or (B and D) the number of invaded cells were counted. (E and F) SNU601 and (G and H) AGS cells exposed to growth medium adjusted to $\mathrm{pH} 7.4,6.5$ or 6.2 for 3 days were harvested and the mRNA expression of the genes encoding (E and G) MMP7 and (F and H) MMP9 was analyzed by real-time PCR. ${ }^{*} \mathrm{P}<0.05,{ }^{* *} \mathrm{P}<0.01$ vs. $\mathrm{pH}$ 7.4. GC, gastric cancer. MMP7, matrix metalloproteinase 7; MMP9, matrix metalloproteinase 9.

incubation and washing, alkaline phosphatase-conjugated streptavidin was added. Then, diflunisal phosphate stock solution and terbium-based detection solution were added, and fluorescence was assessed with a fluorometer (Perkin-Elmer). Calibration and data reduction were performed automatically.

Statistical analysis. All numerical data are presented as the mean \pm SE of at least three independent experiments. Student's t-test was used for simple comparisons, and one-way ANOVA with Tukey's post hoc test was applied for multiple comparisons. $\mathrm{P}<0.05$ was considered to indicate a statistically significant difference.

\section{Results}

Incubation in acidic culture medium increases GC cell invasion. Previous research has revealed that extracellular acidity induces tumor growth, invasion, and metastasis. It was observed that incubation of gastric cancer cell lines AGS and SNU601 in an acidic $\mathrm{pH}$ medium triggered increased invasion of the cells compared to those cultured in normal-pH medium. To detect invasiveness, cells were cultured in culture medium adjusted to $\mathrm{pH} 7.4,6.5$, and 6.2 for $72 \mathrm{~h}$, then the same number of viable cells were obtained and added onto the upper portion of Transwell plates which were coated with Matrigel. After $8 \mathrm{~h}$ for AGS and $24 \mathrm{~h}$ for SNU601 cells, the number of cells that invaded to the lower chamber was counted. The results revealed that the number of cells invading to the lower portion of the Transwell plates increased in the acidic environment (Fig. 1A-D). In addition, the mRNA levels of proteolytic enzymes MMP7 and MMP9, which are known to be involved in cancer cell invasion, were increased, as assessed by real-time PCR (Fig. 1E-H).

Cells cultured in acidic medium increase expression of $K L K 7$ and $K L K 8$. Proteases play crucial roles in cancer invasion and metastasis due to their proteolytic activity to cleave extracellular matrix and adhesion molecules. Although MMPs are known to be essential proteases mediating cell invasion, a possible involvement of other proteases in cancer cell invasion under an acidic environment was explored. Notably, it was revealed that the levels of KLK7 and KLK8 were significantly increased in acidic culture conditions. Acidic $\mathrm{pH}$ culture conditions significantly increased the mRNA levels of KLK7 and KLK8 in both gastric cancer cell lines (Fig. 2A-H). To assess whether increased mRNAs of KLK7 and KLK8 led to increased protein levels, immunoblot assays were performed using cell lysates. When the cells were incubated in acidic medium, the protein levels of KLK8 increased but those of KLK7 decreased (Fig. 2I and J). Since KLKs are proteases mainly secreted into the extracellular space, the protein levels of KLK7 and KLK8 released into the medium were also examined using an ELISA assay. As the $\mathrm{pH}$ decreased, the amounts of KLK7 and KLK8 proteins released into the medium significantly increased (Fig. 2K and L). Thus, acidity induced the expression and secretion of KLK7 and KLK8.

Elevation of KLK7 and KLK8 is linked to acidity-induced invasion. Since KLK family members have been revealed 
A SNU601-KLK7 (48 h)

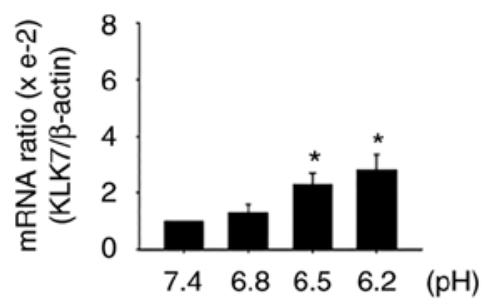

D SNU601-KLK8 (72 h)

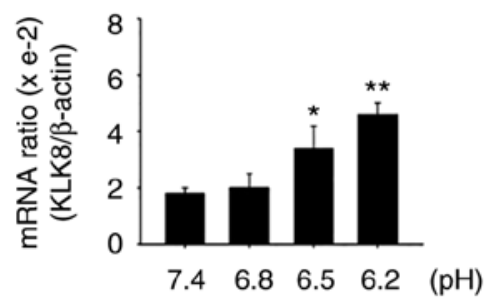

$\mathrm{B}$

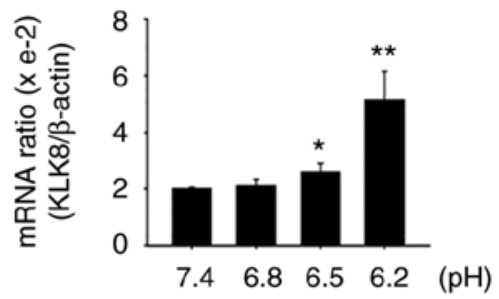

E AGS-KLK7 (48 h)

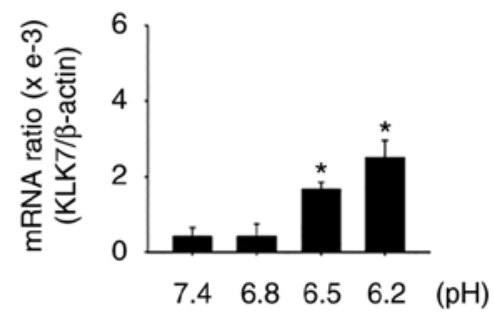

C SNU601-KLK8 (48 h)

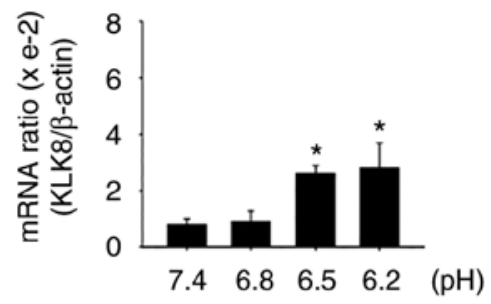

F AGS-KLK7 (72 h)

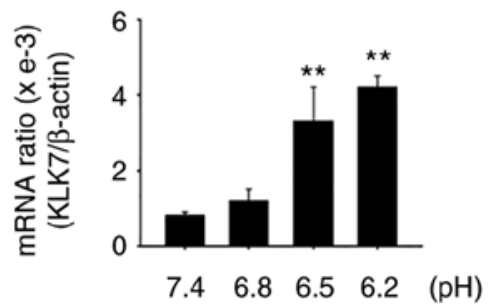

G AGS-KLK8 (48 h)

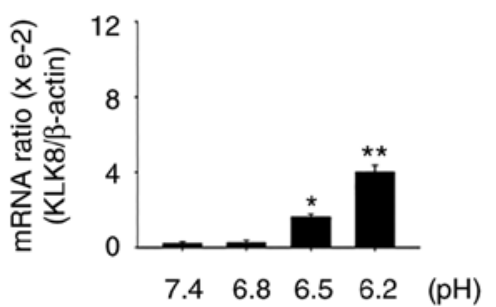

I

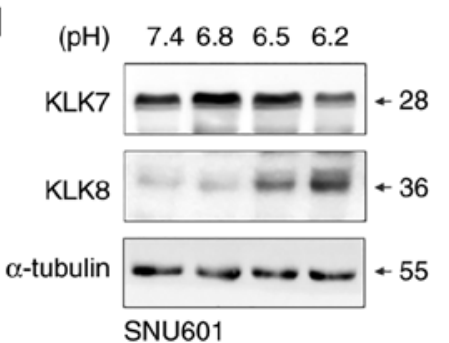

J
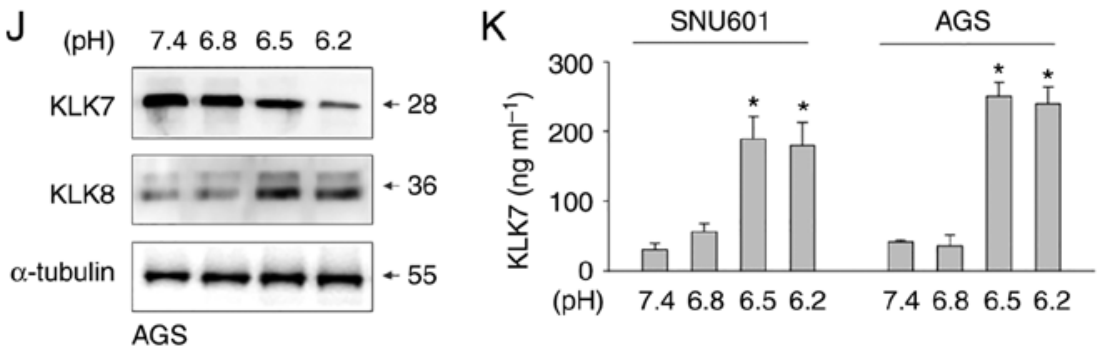

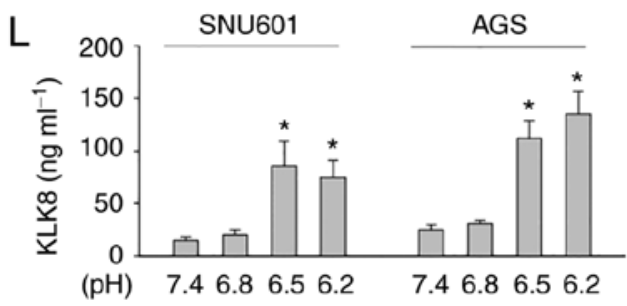

Figure 2. Acidic culture conditions increase expression of KLK7 and KLK8. (A-D) SNU601 and (E-H) AGS cells exposed to normal (pH 7.4) or acidic (pH 6.8, 6.5 and 6.2) medium for (A, C, E and G) $48 \mathrm{~h}$ or (B, D, F and H) $72 \mathrm{~h}$ were harvested and the mRNA expression of the genes encoding (A, B, E and F) KLK7 and (C, D, G and H) KLK8 was analyzed by real-time PCR. SNU601 and AGS cells exposed to pH 7.4, 6.8, 6.5 and 6.2 for $72 \mathrm{~h}$ were collected and total protein extracts were prepared by cell lysis and analyzed by (I and J) immunoblotting with antibodies against KLK7 and KLK8 or medium was subjected to (K and L) ELISA assay to assess secreted KLK7 and KLK8. ${ }^{*} \mathrm{P}<0.05,{ }^{* *} \mathrm{P}<0.01$ vs. pH 7.4. KLK7, kallikrein-related peptidase 7; KLK8, kallikrein-related peptidase 8.

to be involved in malignant phenotypes of certain cancers, it was hypothesized that increased KLK7 and KLK8 in acidic environments would play a role in the acidity-mediated invasion of these cancer cells. To examine this, cells treated with siRNAs specifically silencing KLK7 or KLK8 were exposed to acidic medium. Cells in which KLK7 or KLK8 were silenced exhibited low invasiveness after incubation in acidic $(\mathrm{pH} 6.5)$ culture medium (Fig. 3A and B). The silencing efficiency of the KLK7 and KLK8 siRNAs was confirmed by decreased protein levels (Fig. 3C and D). Thus, increased expression of KLK7 and KLK8 appears to be linked to the enhanced invasiveness of gastric cancer cells. 
A SNU601

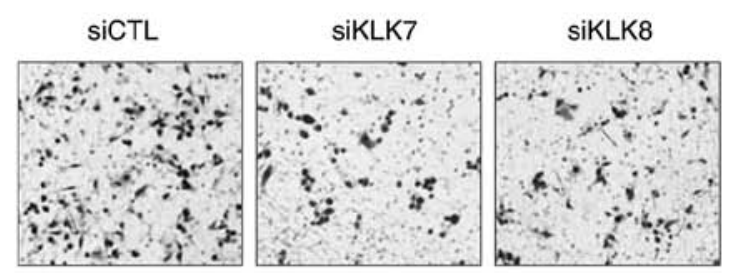

B AGS

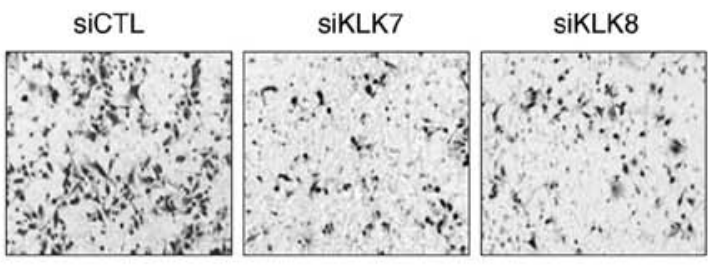

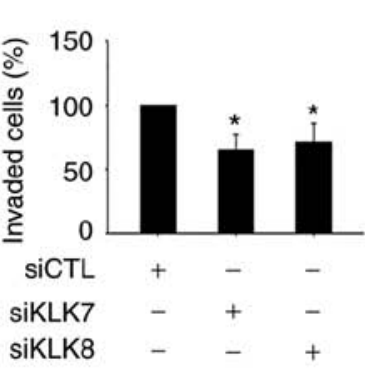

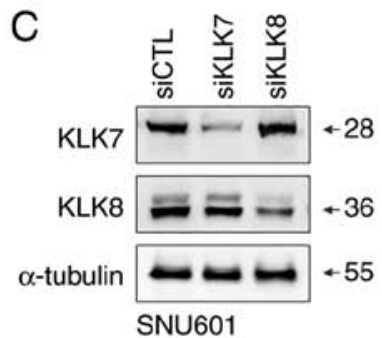

SiKLK8 - $\quad-\quad+$
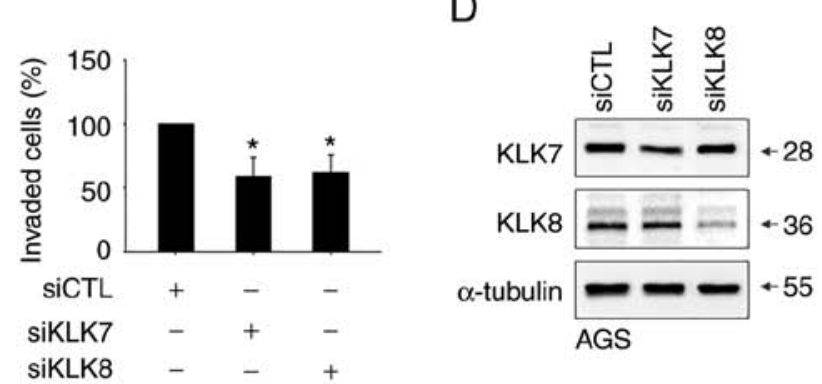

Figure 3. Knockdown of KLK7 and KLK8 decreases acidity-induced migration and invasion. (A and C) SNU601 and (B and D) AGS cells transfected with scrambled small interfering RNA (siCTL), siKLK7, or siKLK8 were exposed to $\mathrm{pH} 6.5$-adjusted medium for $72 \mathrm{~h}$. (A and B) Equal amounts of viable cells were placed into the inner wells of Matrigel-coated Transwell plates, and the invaded SNU601 and AGS cells were detected after further incubation for $18 \mathrm{~h}$ and $8 \mathrm{~h}$, respectively. (C and D) The silencing effect of each siRNA was confirmed by immunoblot analysis after transfection followed by incubation at pH 6.5 for 48 h. ${ }^{*}$ < 0.05 vs. siCTL. KLK7, kallikrein-related peptidase 7; KLK8, kallikrein-related peptidase 8.
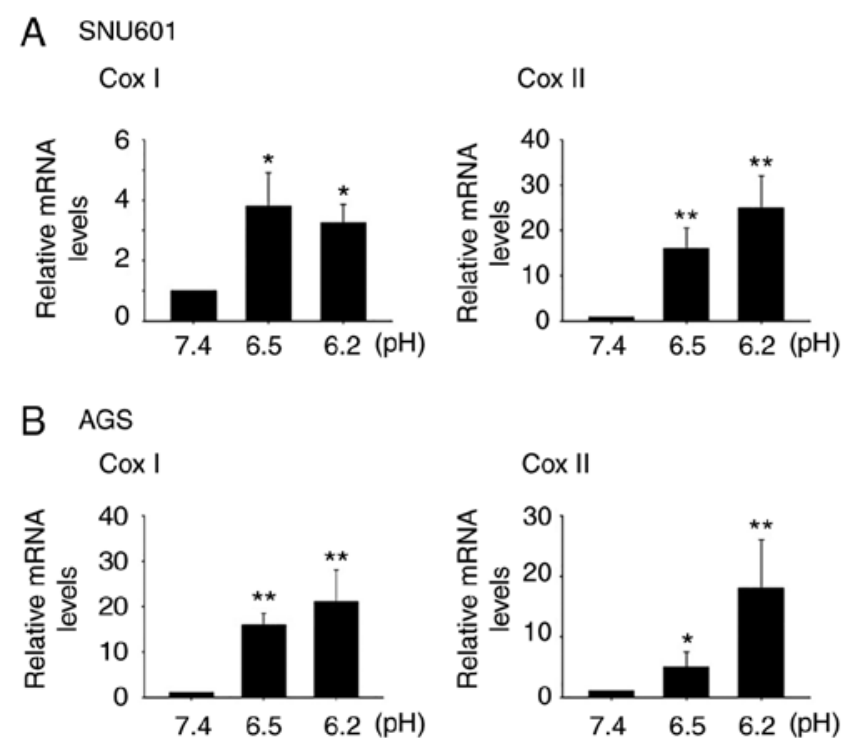

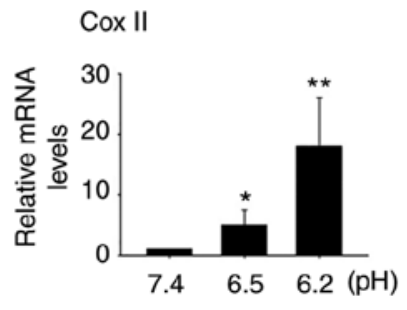

C

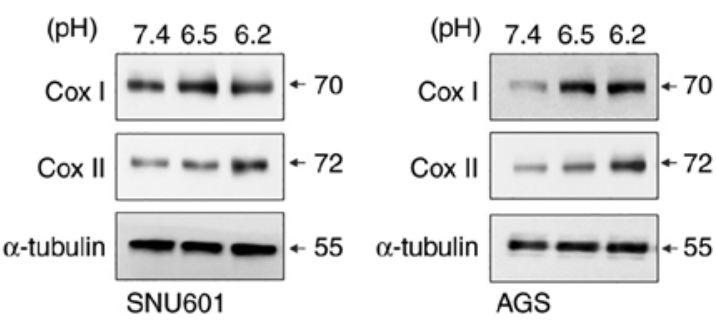

Figure 4. Acidic culture conditions increase the expression of COX1 and COX2. Cells exposed to medium adjusted to $\mathrm{pH} 7.4$, $\mathrm{pH} 6.5$, or $\mathrm{pH} 6.2$ for (A and $\mathrm{B}$ ) $48 \mathrm{~h}$ or (C) $72 \mathrm{~h}$ were harvested and the mRNA expression of the genes encoding COX1 and COX2 was analyzed by (A and B) real-time PCR or by (C) immunoblotting with antibodies against $\mathrm{COX} 1$ and $\mathrm{COX} 2{ }^{*} \mathrm{P}<0.05,{ }^{* *} \mathrm{P}<0.01$ vs. $\mathrm{pH} 7.4$. COX, cyclooxygenase.

Induction of COX1 and COX2 is involved in acidity-mediated $K L K 7$ and KLK8 expression. To understand the regulatory mechanisms involved in acidity-mediated KLK7 and KLK8 expression, potential upstream regulators were examined. Previously, acidity was revealed to stimulate inflammatory responses via the cyclooxygenase (COX) pathway. Consistent with a previous study, acidic culture conditions elevated mRNA and protein levels of COX2 in both GC cell lines (20). In addition, the mRNA and protein expression of COX1, a constitutive isoform, increased (Fig. 4). Thus, the role of COXs in KLK induction was examined by assessing the effect of COX inhibi- tors on the expression of KLK7 and KLK8. Upon exposure to sulindac, a broad COX inhibitor, acidity-induced mRNA expression of KLK7 and KLK8 was reduced. In contrast, exposure to selective COX2 inhibitor NS398 had little effect on the level of these peptidases (Fig. 5A-D). Likewise, the effect on cellular invasion at acidic $\mathrm{pH}$ was partially reduced by sulindac, but not by NS398 (Fig. 5E and F). This indicated that the COX pathway is involved in acidity-induced KLK7 and KLK8 expression, and that COX1 plays a more important role than COX2 in the expression of KLK7 and KLK8. To confirm this, cells transfected with siRNAs silencing COX1 or COX2 
A

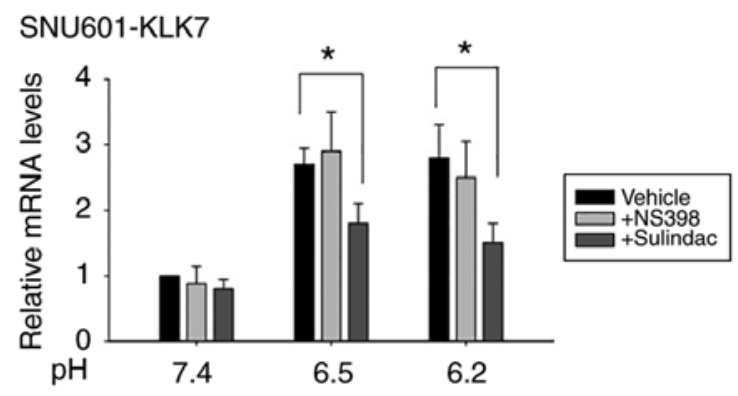

C AGS-KLK7

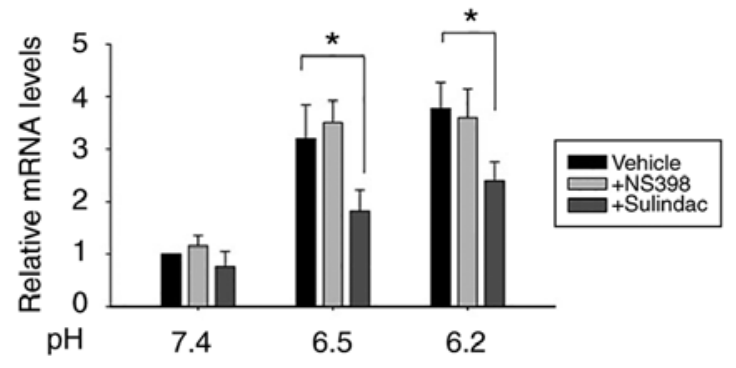

E SNU601

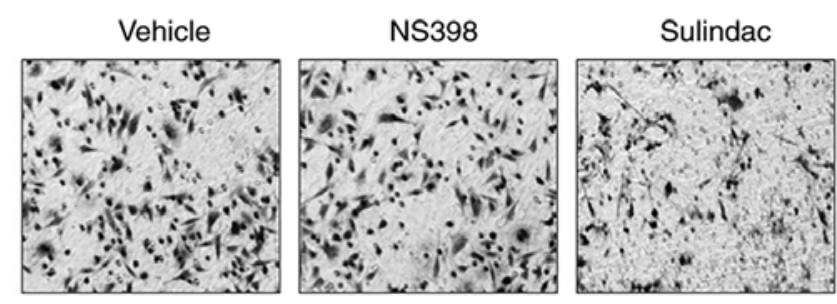

F AGS

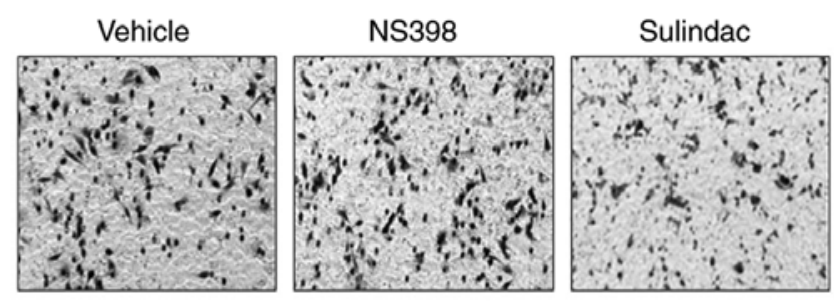

B SNU601-KLK8

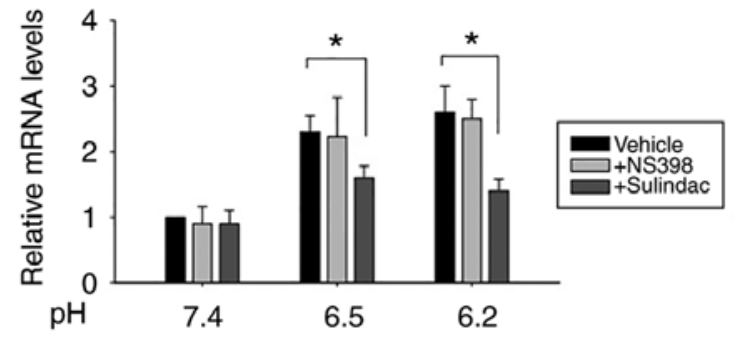

D AGS-KLK8
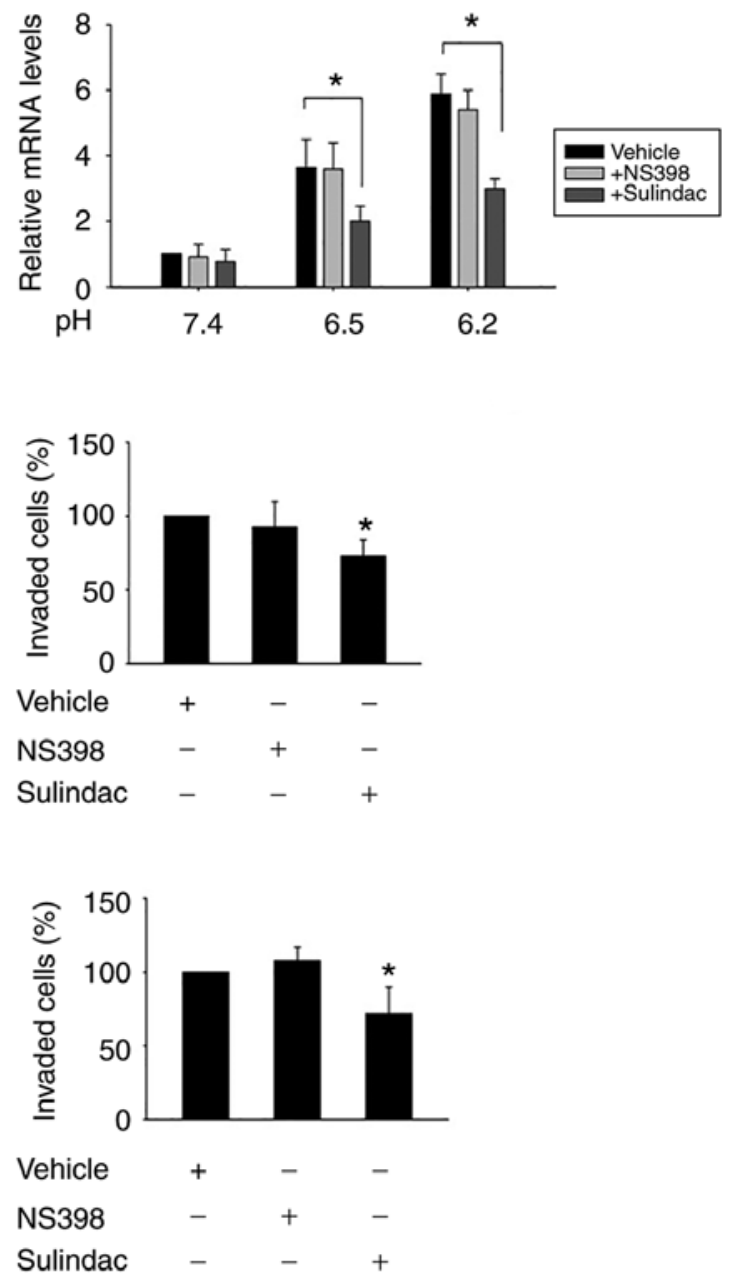

Figure 5. General COX inhibitor, sulindac reduces acidity-induced KLK7 and KLK8 expression, and invasion of GC cells. (A-D) Cells were exposed to pH 7.4, 6.5 and 6.2 in the absence or presence of $20 \mu \mathrm{M} \mathrm{NS} 398$ or $100 \mu \mathrm{M}$ sulindac for $72 \mathrm{~h}$, and the mRNA expression of the genes encoding KLK7 and KLK8 was analyzed by real-time PCR. (E and F) Cells exposed to pH 6.5 in the absence or presence of $20 \mu \mathrm{M}$ NS398 or $100 \mu \mathrm{M}$ sulindac for $72 \mathrm{~h}$ was counted and equal amounts of viable cells were placed into the inner wells of Matrigel-coated Transwell plates, and the invasive ability was assessed by counting cells invading through the membrane after further incubation of $18 \mathrm{~h}$ for SNU601 and $8 \mathrm{~h}$ for AGS cells. "P<0.05 vs. vehicle. COX, cyclooxygenase; KLK7, kallikrein-related peptidase 7; KLK8, kallikrein-related peptidase 8.

were exposed to acidic culture medium, and the silencing efficiency was confirmed by decreased protein levels (Fig. 6C). Knockdown of COX1, but not COX2 partially reduced the mRNA expression of KLK7 and KLK8 (Fig. 6A and B).

\section{Discussion}

Previously, we reported that acidic culture conditions are associated with a decrease in cell growth and an increase in chemoresistance of gastric cancer cells (20). In the present study, it was demonstrated that gastric cancer cells surviving in low-pH environments ( $\mathrm{pH} 6.5$ and 6.2) were more invasive than cells cultured at normal $\mathrm{pH}$, in line with previous studies revealing that extracellular acidity can enhance carcinogenesis and cancer progression by promoting local invasion and metastasis of the tumor $(6,7)$. Although, mild acidic $\mathrm{pH}$ ranges were selected to focus on the acidic $\mathrm{pH}$ that is formed inside solid cancer tissue in this study, in future 


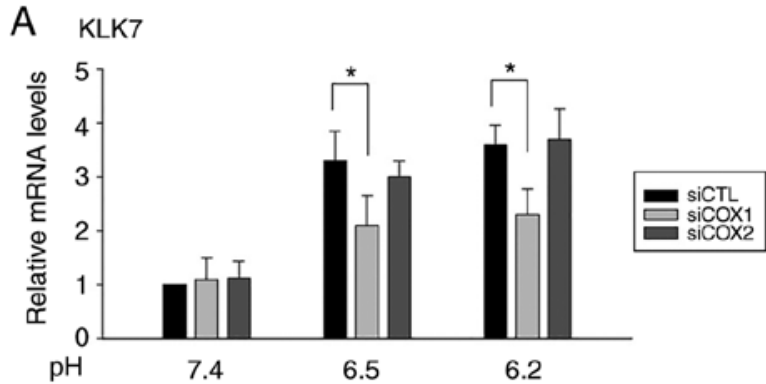

B KLK8
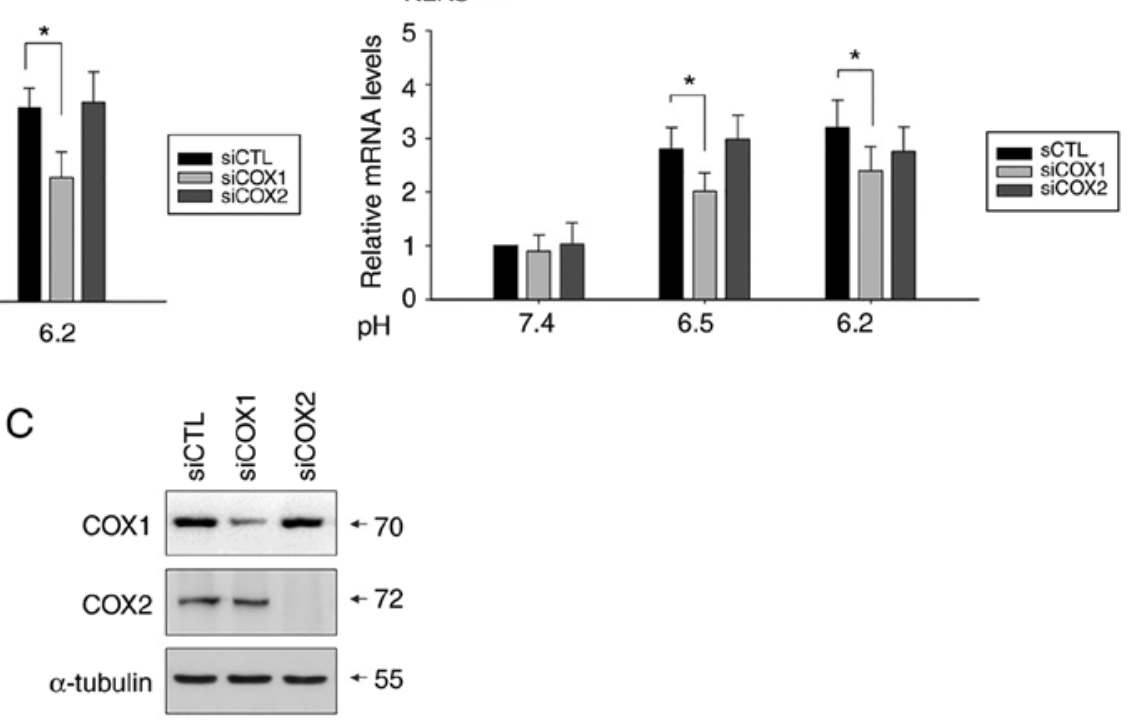

Figure 6. Knockdown of the COX1 gene partially decreases acidity-induced KLK7 and KLK8 expression. (A and B) SNU601 cells transfected with scrambled small interfering RNA (siCTL), siCOX1, or siCOX2 were exposed to $\mathrm{pH}$ 6.5- or 6.2-adjusted medium for $72 \mathrm{~h}$. The mRNA expression of the genes encoding KLK7 and KLK8 was analyzed by real-time PCR. (C) The silencing effect of each siRNA was confirmed by immunoblot analysis after transfection followed by incubation at $\mathrm{pH} 6.5$ for 48 h. "P<0.05 vs. siCTL. COX, cyclooxygenase; KLK7, kallikrein-related peptidase 7; KLK8, kallikrein-related peptidase 8.

studies the effect of lower $\mathrm{pH}$, such as that in the stomach, will be investigated.

An acidic environment can affect the expression of multiple genes in tumor cells. In searching for factors contributing to acidity-mediated invasion, it was revealed that the expression of certain proteases was induced by acidity. Evidence collected over the past several years has revealed that proteases play an essential role in invasion and metastasis of tumor cells because they break bonds with surrounding cells or tissues and degrade the extracellular matrix, thereby allowing tumor cells to penetrate through physical barriers (21). Thus far, various proteases, including cathepsin B, cathepsin D, the urokinase-type plasminogen activator, and several matrix metalloproteases, have been revealed to be involved in tumor invasion and metastasis $(22,23)$. In the present study, it was revealed that GC cells exposed to acidic culture medium had markedly increased expression of KLK family members KLK7 and KLK8, and a considerable amount of these peptidases was secreted into extracellular space. Through siRNA-based gene silencing, it was revealed that these peptidases are involved in the promotion of acidity-mediated migration and invasion.

KLK family members are known to be involved in the regulation of various physiological and pathological processes in human tissues, and certain KLKs play roles in releasing cell-cell adhesion through proteolytic cleavage of junctional proteins, such as desmosomal cadherins (24). Alteration of KLK7 levels is known to be linked to several skin disorders, including dermatitis, psoriasis, and Netherton syndrome (25-27). Notably, overexpression of KLKs is often linked to aggressive phenotypes in multiple cancers. A recent study revealed that an increased KLK7 level was linked to increased proliferation of colorectal cancer cells and associated with poor prognosis or short survival in colon, ovarian and pancreatic cancers (28-30). Furthermore, KLK7 has been described as being potentially involved in metastasis in colorectal and pancreatic cancer, and melanoma (31-34). KLK8, found in numerous normal tissues as well as in body fluids, is also implicated in a variety of malignant tumors, including ovarian, cervical, salivary gland, and lung cancers when aberrantly expressed (35-39). In addition, overexpression of KLK8 is considered to be a potential independent prognostic indicator for CRC. The study on KLK7 and KLK8 is still in the beginning step, and to the best of our knowledge, this is the first study revealing that KLK7 and KLK8 are involved in acidity-mediated gastric cancer cell invasion. Although the link between gastric cancer and KLK7 and KLK8 has not been reported, a previous study indirectly supported the tumor promoting role of KLK7 in gastric cancer, in which inhibition of the growth of transplanted gastric cancer by cisplatin was accompanied by reduction of KLK7 expression (40).

Nevertheless, some studies have demonstrated the opposite effect of KLK7 and KLK8 on cancer. For example, high levels of KLK7 were linked to decreased proliferation in melanoma and a favorable prognosis in melanoma patients $(41,42)$. Increased KLK8 was associated with either a favorable prognosis or no effect on patient outcomes in ovarian cancer $(43,44)$. Since the invasion process requires protease activity to cleave tumor cells from surrounding cells or the extracellular matrix, regulation of cancer cell invasion by KLK may be directly linked to the action of the downstream substrates of KLKs, such as E-cadherin, fibronectin, laminin, IGFBP3, and midkine. Thus, these discrepancies are likely explained by the dominant substrates available for KLK7 or KLK8 in specific environments, although the exact roles of KLK7 and KLK8 in specific cancer tissues and $\mathrm{pH}$ environments requires further investigation through in vivo studies.

Although various important functions of KLKs have been identified, regulatory mechanisms involving KLK expression have not yet been elucidated. In the present study, it was observed that acidic $\mathrm{pH}$ conditions increased the expression 
of COX1 and COX2 in GC cells. It was hypothesized that the acidity would regulate KLK7 and KLK8-mediated invasiveness through COX induction. Previously, acidity-induced COX2 expression was also observed in oral cells (45). COX is well established to play a crucial role in a wide range of inflammatory responses, in which acidity also plays roles. Extracellular acidity triggers activation of immune responses in multiple immune cells, endothelial cells, and fibroblasts (46-48), and many chronic inflammatory diseases involve acidic $\mathrm{pH}$ regions (49). Notably, the inflammatory response acts as a critical factor affecting carcinogenesis and cancer progression. Therefore, the present study may provide an explanation for the induction of inflammatory responses and the increase in tumor invasion in acidic environments, and in further study, a more specific link between acidity-mediated inflammation and tumor invasiveness is under investigation by evaluating the expression of inflammatory-related genes including interleukin 8 and c-Myc.

In the present study, it was demonstrated that an acidic environment could increase COX1-regulated KLK7 and KLK8 expression, and this event contributed to the acidity-induced promotion of GC cell invasion. This study indicates KLK7 and KLK8 as potential targets for anticancer therapies in acidic tumor microenvironments.

\section{Acknowledgements}

We would like to thank Ms Jeong-Eun Choi and Dr Mi-Rae Lee for their excellent technical assistance.

\section{Funding}

This research was supported by the Basic Science Research Program through the National Research Foundation of Korea (NRF) funded by the Ministry of Education (NRF-2015R1D1A1A01060533 and NRF-2018R1D1A1B07046430).

\section{Availability of data and materials}

The datasets used during the present study are available from the corresponding author upon reasonable request.

\section{Authors' contributions}

SIH designed and wrote the manuscript. SCL, KHK and RH performed the experiments and analyzed the data. SIH, MJL and SCL reviewed and edited the manuscript. All authors approved the final manuscript and agree to be accountable for all aspects of the research in ensuring that the accuracy or integrity of any part of the work are appropriately investigated and resolved.

\section{Ethics approval and consent to participate}

Not applicable.

\section{Patient consent for publication}

Not applicable.

\section{Competing interests}

The authors declare that they have no competing interests.

\section{References}

1. Hanahan D and Weinberg RA: Hallmarks of cancer: The next generation. Cell 144: 646-674, 2011.

2. Lazebnik Y: What are the hallmarks of cancer? Nat Rev Cancer 10: 232-233, 2010

3. Seyfried TN and Huysentruyt LC: On the origin of cancer metastasis. Crit Rev Oncog 18: 43-73, 2013.

4. Tannock IF and Rotin D: Acid pH in tumors and its potential for therapeutic exploitation. Cancer Res 49: 4373-4384, 1989.

5. Moellering RE, Black KC, Krishnamurty C, Baggett BK, Stafford P, Rain M, Gatenby RA and Gillies RJ: Acid treatment of melanoma cells selects for invasive phenotypes. Clin Exp Metastasis 25: 411-425, 2008.

6. Estrella V, Chen T, Lloyd M, Wojtkowiak J, Cornnell HH, Ibrahim-Hashim A, Bailey K, Balagurunathan Y, Rothberg JM, Sloane BF, et al: Acidity generated by the tumor microenvironment drives local invasion. Cancer Res 73: 1524-1535, 2013.

7. Gatenby RA and Gillies RJ: A microenvironmental model of carcinogenesis. Nat Rev Cancer 8: 56-61, 2008.

8. Peppicelli S, Bianchini F, Torre E and Calorini L: Contribution of acidic melanoma cells undergoing epithelial-to-mesenchymal transition to aggressiveness of non-acidic melanoma cells. Clin Exp Metastasis 31: 423-433, 2014.

9. Hjelmeland AB, Wu Q, Heddleston JM, Choudhary GS, MacSwords J, Lathia JD, McLendon R, Lindner D, Sloan A and Rich JN: Acidic stress promotes a glioma stem cell phenotype. Cell Death Differ 18: 829-840, 2011.

10. Sevenich L and Joyce JA: Pericellular proteolysis in cancer. Genes Dev 28: 2331-2347, 2014.

11. Darmoul D, Gratio V, Devaud H, Peiretti F and Laburthe M: Activation of proteinase-activated receptor 1 promotes human colon cancer cell proliferation through epidermal growth factor receptor transactivation. Mol Cancer Res 2: 514-522, 2004.

12. Darmoul D, Marie JC, Devaud H, Gratio V and Laburthe M: Initiation of human colon cancer cell proliferation by trypsin acting at protease-activated receptor-2. Br J Cancer 85: 772-779, 2001.

13. Gratio V, Loriot C, Virca GD, Oikonomopoulou K, Walker F, Diamandis EP, Hollenberg MD and Darmoul D: Kallikrein-related peptidase 14 acts on proteinase-activated receptor 2 to induce signaling pathway in colon cancer cells. Am J Pathol 179: 2625-2636, 2011.

14. Ramsay AJ, Reid JC, Adams MN, Samaratunga $\mathrm{H}$, Dong Y, Clements JA and Hooper JD: Prostatic trypsin-like kallikrein-related peptidases (KLKs) and other prostate-expressed tryptic proteinases as regulators of signalling via proteinase-activated receptors (PARs). Biol Chem 389: 653-668, 2008.

15. Loessner D, Goettig P, Preis S, Felber J, Bronger H, Clements JA, Dorn J and Magdolen V: Kallikrein-related peptidases represent attractive therapeutic targets for ovarian cancer. Expert Opin Ther Targets 22: 745-763, 2018.

16. Avgeris M and Scorilas A: Kallikrein-related peptidases (KLKs) as emerging therapeutic targets: Focus on prostate cancer and skin pathologies. Expert Opin Ther Targets 20: 801-818, 2016.

17. Kryza T, Silva ML, Loessner D, Heuze-Vourc'h N and Clements JA: The kallikrein-related peptidase family: Dysregulation and functions during cancer progression. Biochimie 122: 283-299, 2016.

18. Livak KJ and Schmittgen TD: Analysis of relative gene expression data using real-time quantitative PCR and the 2(-Delta Delta C(T)) method. Methods 25: 402-408, 2001.

19. Shaw JL and Diamandis EP: Distribution of 15 human kallikreins in tissues and biological fluids. Clin Chem 53: 1423-1432, 2007.

20. Hong R and Han SI: Extracellular acidity enhances tumor necrosis factor-related apoptosis-inducing ligand (TRAIL)-mediated apoptosis via DR5 in gastric cancer cells. Korean J Physiol Pharmacol 22: 513-523, 2018

21. Chambers AF and Matrisian LM: Changing views of the role of matrix metalloproteinases in metastasis. J Natl Cancer Inst 89: 1260-1270, 1997.

22. Tang $L$ and Han $X$ : The urokinase plasminogen activator system in breast cancer invasion and metastasis. Biomed Pharmacother 67: 179-182, 2013. 
23. Duffy MJ: The role of proteolytic enzymes in cancer invasion and metastasis. Clin Exp Metastasis 10: 145-155, 1992.

24. Caubet C, Jonca N, Brattsand M, Guerrin M, Bernard D, Schmidt R, Egelrud T, Simon M and Serre G: Degradation of corneodesmosome proteins by two serine proteases of the kallikrein family, SCTE/KLK5/hK5 and SCCE/KLK7/hK7. J Invest Dermatol 122: 1235-1244, 2004.

25. Komatsu N, Saijoh K, Kuk C, Liu AC, Khan S, Shirasaki F, Takehara K and Diamandis EP: Human tissue kallikrein expression in the stratum corneum and serum of atopic dermatitis patients. Exp Dermatol 16: 513-519, 2007.

26. Descargues P, Deraison C, Bonnart C, Kreft M, Kishibe M, Ishida-Yamamoto A, Elias P, Barrandon Y, Zambruno G, Sonnenberg A and Hovnanian A: Spink5-deficient mice mimic Netherton syndrome through degradation of desmoglein 1 by epidermal protease hyperactivity. Nat Genet 37: 56-65, 2005.

27. Ekholm E and Egelrud T: Stratum corneum chymotryptic enzyme in psoriasis. Arch Dermatol Res 291: 195-200, 1999.

28. Dorn J, Gkazepis A, Kotzsch M, Kremer M, Propping C, Mayer K, Mengele K, Diamandis EP, Kiechle M, Magdolen V and Schmitt M: Clinical value of protein expression of kallikrein-related peptidase 7 (KLK7) in ovarian cancer. Biol Chem 395: 95-107, 2014.

29. Devetzi M, Trangas T, Scorilas A, Xynopoulos D and Talieri M: Parallel overexpression and clinical significance of kallikrein-related peptidases 7 and 14 (KLK7KLK14) in colon cancer. Thromb Haemost 109: 716-725, 2013.

30. Iakovlev V, Siegel ER, Tsao MS and Haun RS: Expression of kallikrein-related peptidase 7 predicts poor prognosis in patients with unresectable pancreatic ductal adenocarcinoma. Cancer Epidemiol Biomarkers Prev 21: 1135-1142, 2012.

31. Rezze GG, Fregnani JH, Duprat J and Landman G: Cell adhesion and communication proteins are differentially expressed in melanoma progression model. Hum Pathol 42: 409-418, 2011

32. Talieri M, Mathioudaki K, Prezas P, Alexopoulou DK Diamandis EP, Xynopoulos D, Ardavanis A, Arnogiannaki N and Scorilas A: Clinical significance of kallikrein-related peptidase 7 (KLK7) in colorectal cancer. Thromb Haemost 101: 741-747, 2009.

33. Johnson SK, Ramani VC, Hennings L and Haun RS: Kallikrein 7 enhances pancreatic cancer cell invasion by shedding E-cadherin. Cancer 109: 1811-1820, 2007.

34. Delaunay T, Deschamps L, Haddada M, Walker F, Soosaipillai A, Soualmia F, El Amri C, Diamandis EP, Brattsand M, Magdolen V and Darmoul D: Aberrant expression of kallikrein-related peptidase 7 is correlated with human melanoma aggressiveness by stimulating cell migration and invasion. Mol Oncol 11 1330-1347, 2017

35. Kishi T, Grass L, Soosaipillai A, Shimizu-Okabe C and Diamandis EP: Human kallikrein 8: Immunoassay development and identification in tissue extracts and biological fluids. Clin Chem 49: 87-96, 2003.

36. Planque C, Choi YH, Guyetant S, Heuze-Vourc'h N, Briollais L and Courty Y: Alternative splicing variant of kallikrein-related peptidase 8 as an independent predictor of unfavorable prognosis in lung cancer. Clin Chem 56: 987-997, 2010.
37. Darling MR, Tsai S, Jackson-Boeters L, Daley TD and Diamandis EP: Human kallikrein 8 expression in salivary gland tumors. Head Neck Pathol 2: 169-174, 2008.

38. Cane S, Bignotti E, Bellone S, Palmieri M, De las Casas L, Roman JJ, Pecorelli S, Cannon MJ, O'brien T and Santin AD: The novel serine protease tumor-associated differentially expressed gene-14 (KLK8/Neuropsin/Ovasin) is highly overexpressed in cervical cancer. Am J Obstet Gynecol 190: 60-66, 2004.

39. Magklara A, Scorilas A, Katsaros D, Massobrio M, Yousef GM, Fracchioli S, Danese S and Diamandis EP: The human KLK8 (neuropsin/ovasin) gene: Identification of two novel splice variants and its prognostic value in ovarian cancer. Clin Cancer Res 7: 806-811, 2001.

40. Zhuang GF, Tan Y, Yang YZ, Zhang JW and Tang J: Experiment research of cisplatin implants inhibiting transplantation tumor growth and regulating the expression of KLK7 and E-cad of tumor-bearing mice with gastric cancer. Asian Pac J Trop Med 9: 606-609, 2016

41. Yu Y, Prassas I, Dimitromanolakis A and Diamandis EP: Novel biological substrates of human kallikrein 7 identified through degradomics. J Biol Chem 290: 17762-17775, 2015.

42. Martins WK, Esteves GH, Almeida OM, Rezze GG, Landman G, Marques SM, Carvalho AF, L Reis LF, Duprat JP and Stolf BS: Gene network analyses point to the importance of human tissue kallikreins in melanoma progression. BMC Med Genomics 4: 76 , 2011.

43. Borgono CA, Kishi T, Scorilas A, Harbeck N, Dorn J, Schmalfeldt B, Schmitt M and Diamandis EP: Human kallikrein 8 protein is a favorable prognostic marker in ovarian cancer. Clin Cancer Res 12: 1487-1493, 2006.

44. Ahmed N, Dorn J, Napieralski R, Drecoll E, Kotzsch M, Goettig P, Zein E, Avril S, Kiechle M, Diamandis EP, et al: Clinical relevance of kallikrein-related peptidase 6 (KLK6) and 8 (KLK8) mRNA expression in advanced serous ovarian cancer. Biol Chem 397: 1265-1276, 2016.

45. Cha SH, Park JE, Kwak JO, Kim HW, Kim JB, Lee KY and Cha YN: Attenuation of extracellular acidic $\mathrm{pH}$-induced cyclooxygenase-2 expression by nitric oxide. Mol Cells 19: 232-238, 2005.

46. Riemann A, Ihling A, Thomas J, Schneider B, Thews O and Gekle M: Acidic environment activates inflammatory programs in fibroblasts via a cAMP-MAPK pathway. Biochim Biophys Acta 1853: 299-307, 2015

47. Dong L, Li Z, Leffler NR, Asch AS, Chi JT and Yang LV: Acidosis activation of the proton-sensing GPR4 receptor stimulates vascular endothelial cell inflammatory responses revealed by transcriptome analysis. PLoS One 8: e61991, 2013.

48. Etulain J, Negrotto S, Carestia A, Pozner RG, Romaniuk MA, D'Atri LP, Klement GL and Schattner M: Acidosis downregulates platelet haemostatic functions and promotes neutrophil proinflammatory responses mediated by platelets. Thromb Haemost 107: 99-110, 2012

49. Naghavi M, John R, Naguib S, Siadaty MS, Grasu R, Kurian KC, van Winkle WB, Soller B, Litovsky S, Madjid M, et al: $\mathrm{pH}$ Heterogeneity of human and rabbit atherosclerotic plaques; a new insight into detection of vulnerable plaque. Atherosclerosis 164: 27-35, 2002. 